\title{
Comparative clinicopathological and immunohistochemical study of ras and p53 in flat and polypoid type colorectal tumours
}

\author{
M Yukawa, T Fujimori, S Maeda, M Tabuchi, K Nagasako
}

Second Department of Pathology, Kobe University, Kobe, Japan

M Yukawa

T Fujimori

S Maeda

Tokyo Kyosai Hospital, Tokyo, Japan M Tabuchi

Institute of Gastroenterology, Tokyo Women's Medical College, Tokyo, Japan K Nagasako

Correspondence to: Dr M Yukawa, Department of Pathology, Department of Path 7-5-1 Kusunoki-cho Chuo-ku, Kobe, Japan. Accepted for publication 21 December 1993

\begin{abstract}
Mutations in oncogenes and tumour suppressor genes may have an important oncogenic role. Although flat type tumours have been frequently detected in recent years, ras and p53 expressions have not been studied in these tumours. Using a monoclonal and polyclonal antibody to the ras p21 and p53 product, paraffin wax embedded sections of 98 colorectal tumours (43 cases of the flat type colorectal tumour and 55 cases of polypoid type tumour) were stained using the immunoperoxidase technique. Staining was evaluated by light microscopic examination. Positive staining rate of ras p21 for the flat type was $0 \%$; for the polypoid type, it was $60 \%$ in cancer with submucosal invasion, $82 \%$ in adenoma with high grade dysplasia, and $0 \%$ in adenoma with low grade dysplasia. The positive staining rate of p53 for the flat type was $\mathbf{5 0 \%}$ in submucosal cancer, $9 \%$ in adenoma with high grade dysplasia, and $0 \%$ in adenoma with low grade dysplasia. For the polypoid type, it was $\mathbf{4 0} \%$ in submucosal cancer, $12 \%$ in adenoma with high grade dysplasia, and $0 \%$ in adenoma with low grade dysplasia. The intermediate staining rate of p53 in the polypoid type was $20 \%$ in submucosal cancer and $41 \%$ in adenoma with high grade dysplasia. It was seen that p53 was
\end{abstract}

\begin{tabular}{|c|c|c|c|}
\hline & Shape & $\begin{array}{l}\text { Macroscopic } \\
\text { classification }\end{array}$ & $\begin{array}{l}\text { Microscopic } \\
\text { classification }\end{array}$ \\
\hline Flat type & $\mathrm{mm}_{\mathrm{mm}}^{\mathrm{m}}$ & $\begin{array}{l}\text { Flat or } \\
\text { flat depressed }\end{array}$ & Tubular \\
\hline \multirow{3}{*}{ Polypoid type } & munerey & $\begin{array}{l}\text { Sessile or } \\
\text { flat elevation }\end{array}$ & $\begin{array}{l}\text { Tubular or } \\
\text { tubulovillous }\end{array}$ \\
\hline & 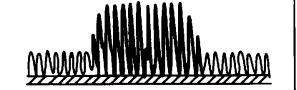 & $\begin{array}{l}\text { Protruded } \\
\text { (villous tumour) }\end{array}$ & Villous \\
\hline & 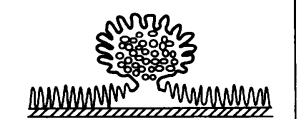 & Pedunculated & $\begin{array}{l}\text { Tubular or } \\
\text { tubulovillous }\end{array}$ \\
\hline
\end{tabular}

Figure 1: Classification of colorectal tumours based on the height of the mucosal layer. Polypoid type cancer, the height of the tumour is more than twice the normal mucosa; flat type cancer, the height of the tumour is below that of the normal mucosa. $M=$ mucosa, $S M=$ submucosa, MM= mucosal muscle. commonly expressed in both flat and polypoid lesions, p21 was not expressed in flat lesions, whereas it was commonly expressed in polypoid neoplasms. In the flat type cancer, a genetic change different from that of the polypoid type cancer is suggested.

(Gut 1994; 35: 1258-1261)

The concept known as the adenomacarcinoma sequence is widely accepted for the pathogenesis of colorectal cancers. ${ }^{1}$ Sequential genetic mutations, including chromosome deletion and loss of suppressor genes found there, have been described by Vogelstein et al who presented one model of carcinogenesis of colorectal cancer in the adenoma carcinoma sequence. ${ }^{2-8}$

Flat type tumours have been frequently detected in recent years. ${ }^{9}$ Based on the height of the mucosal layer, colorectal tumours have been further classified as flat type and polypoid type. The molecular genetic events in flat type tumour are poorly understood. Using a monoclonal antibody to the ras gene product and polymerase chain reaction, we previously reported that no point mutation of ras gene was detected in flat type colorectal tumours. ${ }^{10}$

The aim of this study was to evaluate the expression of ras and p53 proteins in flat type colorectal tumours, in comparison with the polypoid type, as determined by immunostaining with the monoclonal antibody rap 5 and polyclonal antibody CM1.

\section{Methods}

HISTOLOGICAL CLASSIFICATION

Specimens excised by surgery or polypectomy, after being fixed in formalin, were embedded in paraffin wax, sliced into $4 \mu \mathrm{m}$ thick sections, and stained with haematoxylin and eosin and immunostaining. Histologically, flat type tumours do not protrude, extend horizontally, and have tubular cytological features. Morphological classification of colorectal tumours was carried out. The height of the tumour was measured using an Olympus automatic analyser SP500. When the tumour height was similar to or less than that of the normal mucosa, it was classified as flat type. ${ }^{11}$ Others were classified as polypoid type (Figs 1 and 2). Both flat type and polypoid type tumours were classified into cancer with submucosal invasion, adenoma with high 

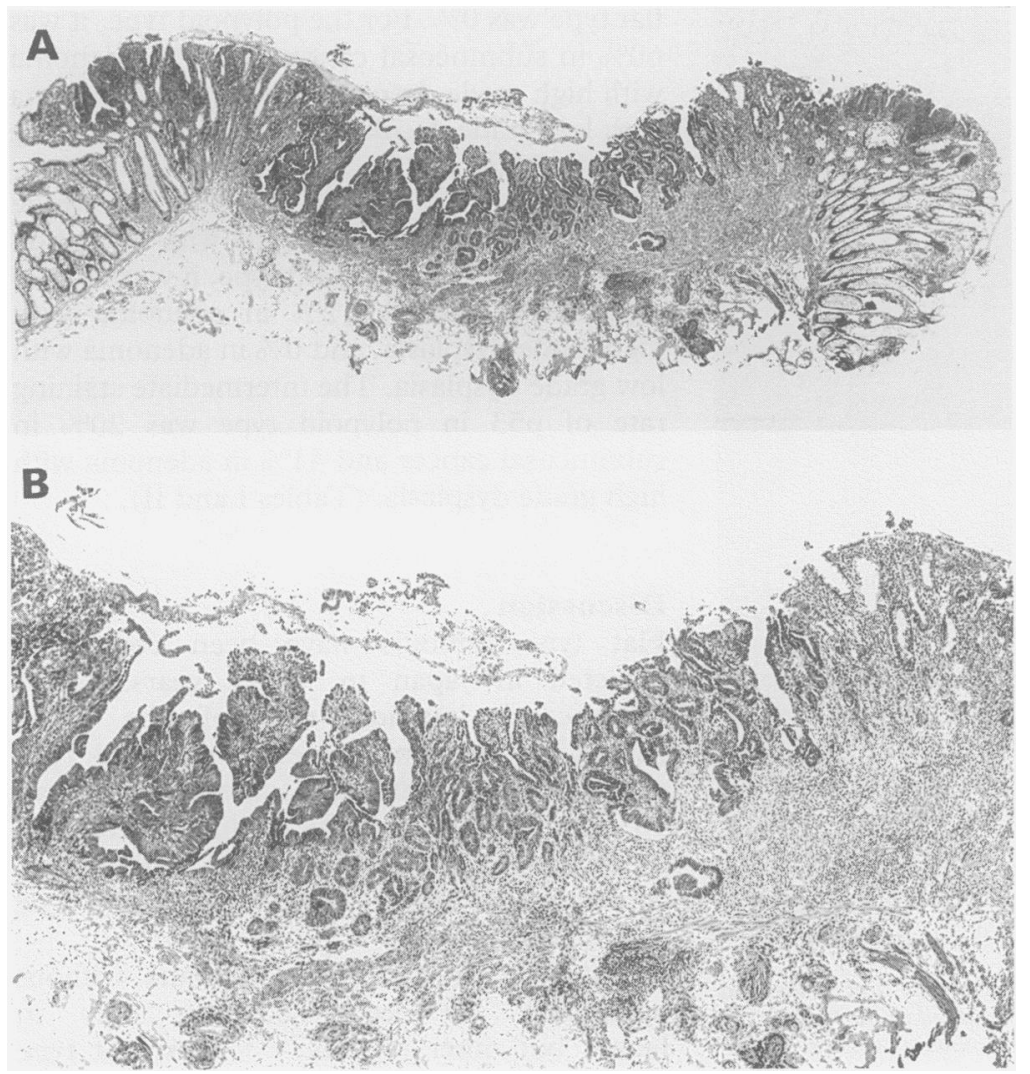

Figure 2: Microscopic picture showing a flat type tumour. The height of the tumour is below that of the normal mucosa (haematoxylin and eosin stain) $((A)$, original magnification $\times 10$; $(B)$ original magnification $\times 40)$.

grade dysplasia or adenoma with low grade dysplasia.

\section{CASE SELECTION}

A total of 43 flat type and 55 polypoid type colorectal tumours excised at Tokyo Women's Medical College Gastrointestinal Center, Tokyo Kyosai Hospital, Kobe University Hospital, and related institutions were selected for this study.

\section{IMMUNOHISTOCHEMICAL METHODS}

Immunostaining was performed using the labelled avidin-biotin technique previously described. ${ }^{12}$ Briefly, deparaffinised, rehydrated sections were treated with $3 \%$ hydrogen peroxide for 13 minutes to block endogenous peroxidase activity. After rinsing, slides were incubated with normal goat serum for 20 minutes. Excess serum was drained and sections were incubated with monoclonal anti-ras p21 (rap 5, provided by Dr Schlom, NIH Maryland, USA) at a dilution of 1:50000 for 30 minutes at $4^{\circ} \mathrm{C}$ and polyclonal anti-p53 (NCL-p53-CM1, Novocastra Laboratories, Newcastle upon Tyne, UK) at a dilution of 1:800 for 30 minutes at $4^{\circ} \mathrm{C}$. A biotinylated antirabbit and antimouse IgG as a secondary antibody (DAKO, Carpenteria, CA) was used, followed by peroxidase conjugated streptavidin (DAKO, Carpenteria, CA). The peroxidase reaction was developed using deaminobenzidine tetrahydrochloride, $0.5 \mathrm{mg} / \mathrm{ml}$ with $0.03 \%$ hydrogen peroxide for 10 minutes. Phosphate buffered saline ( $\mathrm{pH} 7 \cdot 6$ ) was used for rinsing between steps. The positive control of ras was the rat red cell leukaemic cell strains (K4d) and of p53 was the osteosarcoma cell strain (HOS); negative controls were normal serum without primary antibodies. All sections were counterstained with haematoxylin and light green, dehydrated, and mounted with coverslips.

\section{STAINING EVALUATION}

Both the distribution (the percentage of positive cells) and the intensity of staining were assessed in a semiquantative fashion. The following system was used to score the number of positive cells: none (not stained): 0 ; focal (<one third of cells stained): 1 ; multifocal (<two thirds of cells stained): 2 ; and diffuse (most cells stained): 3 . The intensity of staining was graded as follows: none (not stained): 0 ; mild (between 0 and 2): 1 ; and strong (clearly identified by $\times 40$ magnification): 2. The score for distribution and intensity were added and graded as follows: 0 , 1, and 2: negative; 3: intermediate; 4 and 5: positive. In addition, cellular location of staining was examined. ${ }^{13}$

\section{DATA ANALYSIS}

Immunohistological results were compared with Fisher's test.

\section{Results}

PATIENTS

There were no statistically significant differences in age distribution between flat type

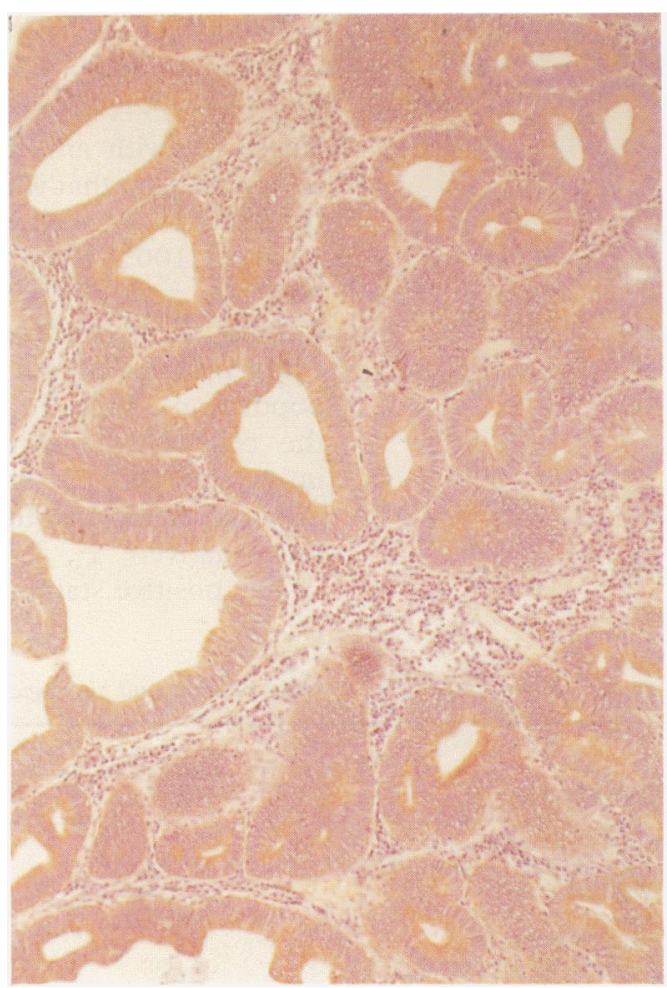

Figure 3: Rap-5 immunostaining of polypoid type cancer classified as positive. Immunoreactivity is localised in the cytoplasm of the tumour cells (Avidin-biotin-peroxidase complex stain). 


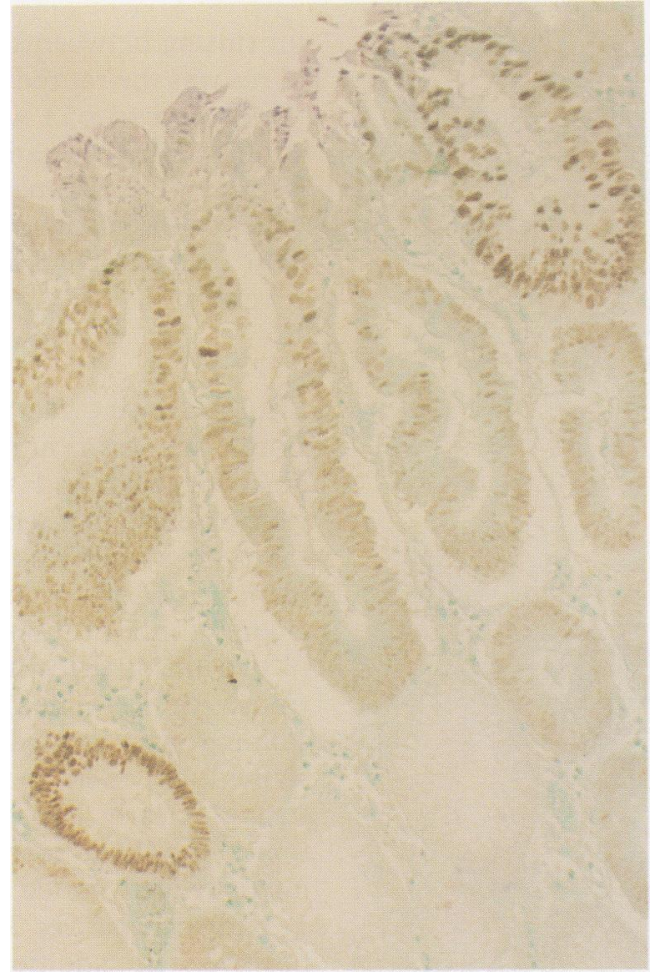

Figure 4: p53 Immunostaining of flat type cancer classified as positive. Immunoreactivity is localised in the nucleus of

and polypoid type tumours. The percentage of men with flat type tumours $(81 \cdot 4 \%)$ was higher than that of patients with polypoid type tumours $(65.5 \%)$. The mean size of the flat type cancers $(9.5 \mathrm{~mm})$ in submucosal cancer was smaller than that of the polypoid type cancers $(15 \cdot 2 \mathrm{~mm})$. Flat type tumours in the ascending and transverse colon $(48.8 \%)$ were more frequent than polypoid type tumours $(18 \cdot 2 \%)$.

RAS AND p53 POSITIVE STAINING RATE Reactivity with anti-ras p21 was confined to the cytoplasm; that with anti-p53 antibody was confined to the cell nucleus. In the positive control, $100 \%$ of the cells were positive. Negative control sections did not show any staining. In all positive cases, ras p21 and p53 overexpression was confined to the tumour cell population (Figs 3 and 4): when present, the cells of the tumour stroma, including inflammatory cells and blood vessels, were negative. All normal tissue adjacent to tumours was negative.

The positive staining rate of ras $\mathrm{p} 21$ for the

TABLE I Comparison of ras staining patterns and histological type of colorectal tumour

$\begin{array}{llll}\hline & \multicolumn{3}{l}{\text { ras-Staining (No of tumours (\%)) }} \\$\cline { 2 - 4 } \text {$\left.Histological type } & \text { Negative } & \text { Intermediate } & \text { Positive } \\ \hline \text { Flat type of tumour } & 12(100) & 0(0) & 0(0) \\ \quad \text { Submucosal cancer }(\mathrm{n}=12) & 11(100) & 0(0) & 0(0) \\ \quad \text { High }(\mathrm{n}=11) & 20(100) & 0(0) & 0(0) \\ \quad \text { Low }(\mathrm{n}=20) & 4(40) & 0(0) & 6(60)\end{array}\right]$

${ }^{\star} \mathrm{p}<0.005$, according to the Fisher's test; high, adenoma with high grade dysplasia; low, adenoma with low grade dysplasia. flat type was $0 \%$. For the polypoid type, it was $60 \%$ in submucosal cancer, $82 \%$ in adenoma with high grade dysplasia, and $0 \%$ in adenoma with low grade dysplasia. The positive staining rate of $\mathrm{p} 53$ for the flat type was $50 \%$ in submucosal cancer, $9 \%$ in adenoma with high grade dysplasia, and $0 \%$ in adenoma with low grade dysplasia. For the polypoid type, it was $40 \%$ in submucosal cancer, $12 \%$ in adenoma with high grade dysplasia, and $0 \%$ in adenoma with low grade dysplasia. The intermediate staining rate of p53 in polypoid type was $20 \%$ in submucosal cancer and $41 \%$ in adenoma with high grade dysplasia. (Tables I and II).

\section{Discussion}

Flat type tumours have been commonly detected in Japan in recent years. ${ }^{14}$ The submucosal invasion rate of the small (under $20 \mathrm{~mm}$ in diameter) polypoid type cancer is low, but flat tumours less than $10 \mathrm{~mm}$ in diameter have a higher tendency to develop advanced cancer. ${ }^{15}$ They differ clinicopathologically from polypoid type tumours.

Flat type or diminutive tumours without protrusion are recognised not only in Japan, but other regions. ${ }^{1617}$ Most flat type and diminutive tumours are hyperplastic neoplasms or adenomas, but a small portion are invasive cancers. Many possibilities are suggested for the genesis of these flat type cancers. Those include, residue of the lesion of a past polypectomy; a large polyp was originally presented, which underwent infarction and autoamputation; the presence of cancer that does not protrude.

The flat type tumours reported in our cases exclude the possibility of pre-existing polypectomy or pre-existing polyp with infarction, as no patient in this study underwent polypectomy and dilated vessels and fibrosis, evidence of pre-existing polyp with infarction were not found under microscopic examination.

Differentiation between de novo carcinoma and the adenoma-carcinoma sequence is difficult because flat cancers may arise from foci of dysplasia within the mucosa just as polypoid cancers arise from dysplasia within polypoid adenomas. This report emphasises the presence of the flat type cancer, which has a higher tendency to develop invasive cancer than the polypoid type cancer.

It is said that activation of the ras gene in colorectal cancer occurs because of point mutation of the base sequences corresponding to the 12th, 13th, and $61 \mathrm{st}$ amino acids. ${ }^{18}$ For recognising the ras $\mathrm{p} 21$, which undergoes overexpression because of these point mutations, we used rap-5, which shows better staining of paraffin wax embedded materials in comparison with $\mathrm{Y}-13-259 .{ }^{19}$ In this study, no expression of ras p21 was seen in flat type cancers. It is suggested that the initiation of flat type cancers differs from that of polypoid cancers. This is supported by similar results reported in cases with ulcerative colitis, which undergo carcinogenesis. ${ }^{20}$ 
TABLE II Comparison of p53 staining patterns and histological type of colorectal tumour

\begin{tabular}{llll}
\hline & \multicolumn{2}{l}{$p 53$ Staining (No of tumours (\%)) } \\
\cline { 2 - 4 } Histological type & Negative & Intermediate & Positive \\
\hline Flat type of tumour & & & \\
$\quad$ Submucosal cancer $(\mathrm{n}=12)$ & $10(50)$ & $0(0)$ & $6(50)$ \\
High $(\mathrm{n}=11)$ & $20(100)$ & $0(0)$ & $1(9)$ \\
$\quad$ Low $(\mathrm{n}=20)$ & $4(40)$ & $0(0)$ & $0(0)$ \\
Polypoid type tumour & $8(47)$ & $2(20)$ & $4(40)$ \\
$\quad$ Submucosal cancer $(\mathrm{n}=10)$ & $28(100)$ & $0(41)$ & $2(12)$ \\
High $(\mathrm{n}=17)$ & & $0(0)$ & $0(0)$ \\
Low $(\mathrm{n}=28)$ & &
\end{tabular}

${ }^{\star} \mathrm{p}<0.005$, according to the Fisher's test; high, adenoma with high grade dysplasia; low, adenoma with low grade dysplasia. research team organised by the Ministry of Health and Welfare. As the results obtained through our study, based on immunostaining, show a tendency similar to those from the study using polymerase chain reaction, we propose flat type colorectal tumour as a new precancerous lesion.

1 Morson SC. Precancerous and early malignant lesion of the large intestine. Br f Surg 1968; 55: 725-31.

2 Bodmer WF, Bailey CJ, Bodmer J, Bussey HJR, Ellis A Gorman P, et al. Localization of the gene for familial adenomatous polyposis on chromosome 5 . Nature $1987 ; 328$ 614-6.

3 Leppert M, Dobbs M, Scambler P. The gene for familia polyposis coli maps to the long arm of chromosome 5 . Science 1987; 238: 1411-3.

p53 Mutations in colorectal cancer include point mutations and deletions of allelic genes, the position of point mutations having four 'hot spots'. ${ }^{21}$ Lane et al produced the monoclonal antibody $\mathrm{PAb} 240$, which reacts with p53 with mutations, but not with normal p53.22 Immunohistochemically positive findings using antibodies PAb240 and PAb1801, which react to both normal and mutated p53, and the results of analysis of point mutations with polymerase chain reaction were compared, and it was concluded that immunohistologically positive tumours undergo point mutation. ${ }^{23}$ As the expression of p53 in normal cells is extremely low, and as its half life is short, normal p53 has not been immunohistologically corroborated, so it is extremely likely that only mutant p53 has been corroborated. Therefore, in this study we used the polyclonal antibody NCL-p53-CM1, which reacts with both normal and mutant $\mathrm{p} 53$, even after formalin fixation and routine processing. In our study of the polypoid type, the positive staining rate was $0 \%$ in adenoma with low grade dysplasia, $12 \%$ in adenoma with high grade dysplasia and $40 \%$ in submucosal cancer. In the flat type also, p53 expression was $0 \%$ in adenoma, $9 \%$ in adenoma with high grade dysplasia, and $50 \%$ in submucosal cancer. No significant difference was seen in p53 abnormality expression rate between polypoid type and the flat type. In the polypoid type, intermediate staining was $20 \%$ in submucosal cancer and $41 \%$ in adenoma with high grade dysplasia. This result may show heterogeneity of polypoid type neoplasms.

Topographic differences in the distribution of genetic abnormalities in colorectal cancers have been reported. ${ }^{24}$ In our data, $33 \%$ of all flat lesions occurred in the rectum and sigmoid, whereas $60 \%$ of the polypoid occurred there. This result may show the discrepancies in genetic abnormalities based on distribution.

Flat type colorectal tumour, now attracting considerable attention in Japan, is being studied in an interdisciplinary manner by a
4 Law DJ, Olschwang S, Monpezat J, et al. Concerted nonsynthetic allelic loss in human colorectal carcinoma. Science 1988; 241: 961-5.

5 Baker SJ, Fearon ER, Nigro JM, O'Connell P, Nakamura Y, Stauffer D, et al. Chromosome 17 deletions and $\mathrm{p} 53$ gene Stauffer D, et al. Chromosome 17 deletions and p53 gene
mutations in colorectal carcinomas. Science 1989; 244: mutation

6 Fearon ER, Cho KR, Nigro JM, Kern SE, Simons JW, gene that is altered in colorectal cancers. Science 1990 247: 49-56.

7 Kinzler KW, Nilbert MC, Vogelstein B, Bryan TM, Levy $\mathrm{DB}$, Smith KJ, et al. Identification of a gene located at chromosome 5q21 that is mutated in colorectal cancers. Science 1991; 251: 1366-9.

8 Fearon ER, Vogelstein B. A genetic model for colorectal tumorigenesis. Cell 1990; 61: 759-67.

9 Kuramoto S, Oohara T. Flat early cancer of large intestine. Cancer 1989; 64: 950-5.

10 Fujimori T, Nagasako K, Satonaka K. Expression of ras oncogene product ( $\mathrm{p}-21)$ and point mutation of Ki-ras codon 12 in superficial early colorectal cancer. (In Japanese.) Stomach and Intestine 1992; 27: 111-7.

11 Nagasako K, Satonaka K, Fujimori T, et al. A clinico-pathological study on the mucosal heights of superficial type (Type II) early colon cancer. (In Japanese.) $f_{p n} \mathcal{f}$ Gastroenterol 1991; 88: 763 .

12 Warnke $R$, Levy $R$. Detection of $T$ and $B$ cell antigens with hybridoma monoclonal antibodies. A biotin-avidin-horseradish peroxidase method. $\mathcal{F}$ Histochem Cytochem 1980 28: 771 .

13 Hirayama D, Fujimori $T$, Satonaka $K$, Nakamura $T$, Kitazawa S, Horio $M$, et al. Immunohistochemical study of epidermal growth factor and transforming growth of epidermal growth factor and transforming growth
factor-beta in the penetrating type of early gastric cancer. factor-beta in the penetrating
Hum Pathol 1992; 23: 681-5.

14 Ishii $H$, Tatsuta M, Tsutsui S, Imanishi K, Otani T, Okuda $\mathrm{S}$, et al. Early depressed adenocarcinomas of the large intestine. Cancer 1992; 69: 2406-10.

15 Tsuruta O, Toyonaga A, Arima N, Irie A, Sasaki E, Morimatsu M, et al. Endoscopic and radiological diagnosis of early colorectal cancer with submucosal invasion. (In Japanese.) Stomach and Intestine 1991; 26: 750-63.

16 Muto T, Bussey HJR, Morson BC. The evolution of cancer of the colon and rectum. Cancer 1975; 36: 2251-70.

17 Spjiet HJ, Frankel NB, Appel MF. The small carcinoma of the large bowel. Am $\mathcal{F}$ Surg Pathol 1979; 3: 39-46.

the large bowel. Am f Surg Pathol 1979; 3: 39-46.
18 Nagata Y, Abe $M$, Kobayashi K. Glycine to aspertic acid mutations at codon 13 of the c-Ki-ras gene in human acid mutations at codon 13 of the c-Ki-ras gene in hum

gastrointestinal cancers. Cancer Res 1990; 50: 480-2.
19 Hirohashi S. Detection of oncogenes and oncogene products. Human Cell 1988; 1: 17-9.

20 Burmer GC, Levine DS, Kulander BG. C-Ki-ras mutation in chronic ulcerative colitis and sporadic colon carcinoma. Gastroenterology 1990; 99: 416-20.

21 Baker SJ, Preisinger AC, Jessup JM, Paraskeva C, Markowitz S, Willson JKV, et al. p53 Gene mutations occur in combination with $17 \mathrm{p}$ allelic deletions as late events in colorectal tumorigenesis. Cancer Res 1990; 50 7717-22.

22 Gannon JV, Greaves R, Iggo R, Lane DP. Activating mutations in $\mathrm{p} 53$ produce a common conformation effect. A monoclonal antibody specific for the mutant form. A monoclonal antibody specif WF, Gannon JV, et al. p53 mutations in colorectal cancer. Proc Natl Acad Sci 1990; 87: 7555-9. proximal colorectal cancer. Lancet 1989; ii: 353-5. Ruppert JM, et al. Identification of a chromosome $18 \mathrm{q}$

23 Rodrigues NR, Rowan A, Smith MEF, Kerr IB, Bodmer

24 Delattre O, Olschwang S, Law DJ, Melot T, Remvikos Y Salmon RJ, et al. Multiple genetic alterations in distal and 